\title{
Digital Necrosis as Initial Manifestation of Multiple Myeloma: An Unusual Case Report
}

\author{
Authors: \\ *Hind Zrikem, Abderrahim Raissi, Salma Amrani Idrissi, Hicham \\ Yahyaoui, Saloua Abbassi, Mustapha Ait Ameur, Mohammed Chakour \\ 1. Department of Laboratory Hematology, IBN SINA Military Hospital, Marrakech, \\ Morocco \\ *Correspondence to dr.hind.zrikem@gmail.com \\ Disclosure: $\quad$ The authors have declared no conflicts of interest. \\ Received: $\quad 21.09 .21$ \\ Accepted: $\quad 10.12 .21$ \\ Keywords: $\quad$ Case report, cryoglobulinemia, multiple myeloma (MM). \\ Citation: $\quad$ EMJ Hematol. 2022; DOI/10.33590/emjhematol/21-00164.
}

\begin{abstract}
Clinical manifestations of multiple myeloma are variable. The authors report a 68-year-old female who presented to the hospital with bilateral digital necrosis and dry gangrenous toes in both left and right feet. She was diagnosed with IgA- $\lambda$ multiple myeloma associated with Type I cryoglobulinaemia. Emergency management consisted in hyperhydration (plasmapheresis was not available) and thromboprophylaxis. Necrotic digits were amputated. Chemotherapy (bortezomib, lenalidomide, and dexamethasone) was started with good initial evolution. This uncommon presentation can easily be missed, and clinicians should be aware of a possible underlying malignancy.
\end{abstract}

\section{INTRODUCTION}

\section{CASE DESCRIPTION}

Multiple myeloma (MM) is a B cell malignancy characterised by abnormal proliferation of plasma cells that expand in the bone marrow and produce a monoclonal Ig, also known as M-protein.' Several signs and symptoms of the condition are related to the excess amounts of the monoclonal Ig such as hyperviscosity syndrome, amyloidosis, renal failure, or autoimmune phenomenon. ${ }^{1}$ The monoclonal Ig can clump together and cause cryoglobulinaemia, usually of Type I. Cutaneous manifestations associated with Type I cryoglobulinaemia include Raynaud syndrome, acrocyanosis, livedo, urticaria, and cold-induced necrotic ulcers of the extremities. ${ }^{2}$ Only few reports of MM with digital necrosis have been described. The authors report the case of a 68-year-old female with MM revealed by gangrene of almost all fingers and toes.
A 68-year-old female, with medical history of neglected non-toxic multinodular goitre but no history of diabetes, venous thromboembolism, ischaemic heart disease, intravenous drug abuse, cigarette smoking, or alcohol dependence, presented to the hospital with a 3-week history of bilateral fingers and toes pain with blackish discoloration.

On admission, she was febrile (temperature: $38.7^{\circ} \mathrm{C}$ ), tachypnoeic (respiratory rate: 42 cycle/min), and tachycardic (pulse rate: 120 / min). Blood pressure and oxygen saturation were normal, as well as her Glasgow coma score (GCS). Her BMI was 23.4 (normal). Physical examination revealed bilateral digital necrosis and dry gangrenous toes $\left(1^{\text {st }}, 2^{\text {nd }}, 3^{\text {rd }}\right.$, 
and $4^{\text {th }}$ ) in both left and right feet (Figure 1) with normal peripheral pulses. Neck exam showed hard painless and nodular goitre. There were no palpable lymph nodes, hepatosplenomegaly, or bone pain. Cardiopulmonary auscultation showed lower-right lung dullness with crackling rales.

The admitting laboratory results were as follows: haemoglobin: $9.9 \mathrm{~g} / \mathrm{dL}$; leukocyte count: $16 \mathrm{giga} / \mathrm{L}$ with 80\% neutrophils; platelet count: 201 giga/L. Erythrocyte sedimentation rate: $90 \mathrm{~mm} / \mathrm{1}^{\mathrm{st}}$ hour; total serum protein: $82 \mathrm{~g} / \mathrm{L}$ (reference range: 62-87); albumin: $18.9 \mathrm{~g} / \mathrm{L}$ (reference range: 35-50); calcium: $85 \mathrm{mg} / \mathrm{L}$ (reference range: 85100); albumin-corrected calcium: $106.14 \mathrm{mg} / \mathrm{L}$; C-reactive protein: $172.00 \mathrm{mg} / \mathrm{L}$ (reference range: 0.0-5.0); creatinine: $205.0 \mathrm{mmol} / \mathrm{L}$ (reference range: 53-115); fasting blood sugar: 4.2 $\mathrm{mmol} / \mathrm{L}$ (reference range 3.9-6.1). Serum protein electrophoresis showed a monoclonal spike of $40.9 \mathrm{~g} / \mathrm{L}$ in the $\beta$ region and immunofixation electrophoresis confirmed that it involves $\lg A \lambda$.

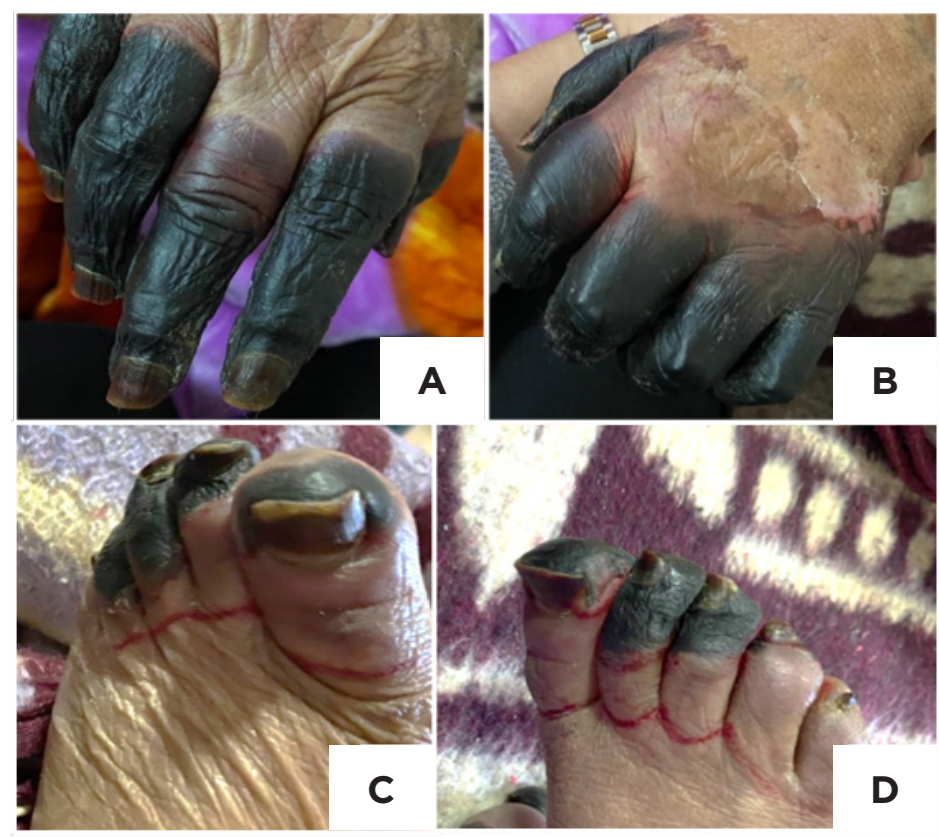

Figure 1: Gangrene in almost all of fingers and toes of the authors' patient, seen on the right hand (A), left hand (B), left foot (C), and right foot (D).

The serum-free $\mathrm{k}$ was $19 \mathrm{mg} / \mathrm{L}$, serum-free $\lambda$ was $125 \mathrm{mg} / \mathrm{L}$, and $\mathrm{k} / \lambda$ ratio was $0.125 \mathrm{mg} / \mathrm{L}$. Urine Bence Jones protein was positive. Cryoglobulin test was positive (qualitative research with cryoprecipitation method). Electrophoresisimmunofixation showed a monoclonal peak and typed the cryoprecipitate as IgA-L. B2 microglobulin was $6.2 \mathrm{mg} / \mathrm{L}$ (reference range: 0.97-2.64 mg/L), and lactate dehydrogenase 984 units/L (reference range: 120-300). Thyroid function was normal. Serological exams for HIV, hepatitis B virus, and hepatitis $C$ virus were negative.

Under the suspicion of a connective tissue disease, a set of analyses were performed, including rheumatoid factor, anti-nuclear, anti-double- stranded DNA, anti-Sjögren's-syndrome-related antigen A autoantibodies, anti-Sjögren syndrome antigen B, anti-nucleosome, anti-histone, antiSmith antigen, anti-U3-ribonucleoprotein, antiJo-1, and anti-Scl-70 antibodies, which were all negative. Serum complement titrations were within normal values. Bone marrow aspirate revealed $30 \%$ infiltration by plasma cells including atypical forms, with no marked reduction in granulopoiesis or erythropoiesis (Figure 2). Conventional karyotype and fluorescent in situ hybridisation were normal.

Chest X-ray showed lower-right lobar shadow. Whole body MRI showed no bone lesions. The diagnosis of MM with Type I cryoglobulinaemia was made. The patient was staged by the 


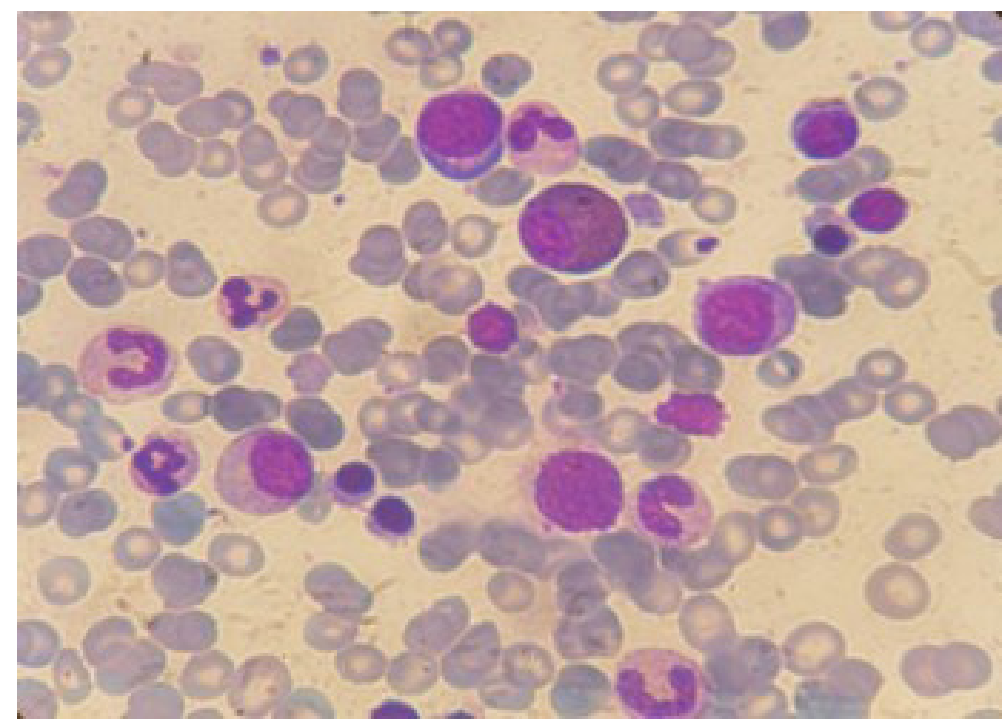

Figure 2: Bone marrow aspirate of our patient showing dystrophic plasma cells.

Revised International Staging System (R-ISS) as Injury Severity Score (ISS) III. Emergency management consisted in hyperhydration (plasmapheresis was not available), intravenous antibiotics, and thromboprophylaxis with lowmolecular-weight heparin. All the necrotic digits were amputated (the decision was made in coordination with vascular surgery staff, the patient, and her family). The patient was started on bortezomib, lenalidomide, and dexamethasone. Initial evolution was good, with normalisation of fever and respiratory symptoms, and no further extension of the acrocyanosis. However, at Day 15 of the second chemotherapy session, she presented to the emergency room with 24 hours history of chest pain and dyspnoea. The diagnosis of massive pulmonary embolism was made, and the patient received curative antithrombotic treatment with low-molecular-weight heparin. Unfortunately, the patient died 48 hours later in the intensive care unit.

\section{DISCUSSION}

MM is a plasma cell dyscrasias afflicting mostly the elderly, over the age of $70 .^{3}$ The International Myeloma Working Group (IMWG) consensus updated the diagnostic criteria for $M M$ to include laboratory biomarkers, radiological, and histological findings in addition to hypercalcaemia, renal failure, anaemia, and bone lesions (CRAB) criteria. ${ }^{4}$ General symptoms such as fatigue, fever, night sweats, weight loss, and bone pain are classic manifestations of MM. Although, this malignancy exhibits a wide range of uncommon presentations, including ocular symptoms (proptosis, optic neuropathy, retinal haemorrhage, and detachment), neurological presentations (cranial nerve palsies, vertigo, and diabetes insipidus related to pituitary involvement), and gastrointestinal manifestations (acute and chronic pancreatitis, mesenteric ischaemia, and hepatosplenomegaly). ${ }^{5}$ In this case, MM was revealed by digital necrosis related to capillary lumen obstruction by Type I cryoglobulin precipitates. Cryoglobulins are abnormal plasma Igs that precipitate at low temperatures and dissolve upon rewarming. According to Brouet et al., ${ }^{6}$ they are classified into three types:

1) Type I cryoglobulins are monoclonal (IgM $>\lg G>\lg A$ ), usually associated with B cell malignancies, most often MM, monoclonal gammopathy of undetermined significance (MGUS), or Waldenström macroglobulinaemia;

2) Type II cryoglobulins are polyclonal Igs associated with monoclonal Igs; and

3) Type III cryoglobulins involve only polyclonal Igs.

Type II and III cryoglobulins are usually $\lg M(\kappa>\lambda)$ and are referred as 'mixed cryoglobulins'. They happen along with hepatitis $C$ virus infection (70-90\%), autoimmune diseases (Sjögren's 
syndrome, followed by lupus and scleroderma), or B cell lymphoid malignancies. This patient's cryoglobulinaemia was typed as IgA-L which is an extremely rare form. Rheumatoid factor activity is often found in mixed cryoglobulinaemia, unlike Type I cryoglobulinaemia, where it is rarely identified. ${ }^{8}$ Clinical manifestations associated with Type I cryoglobulinaemia are mainly cutaneous (purpura, Raynaud's phenomenon, distal ulcers and necrosis, cold urticaria, and livedo). Rheumatologic, neurological, renal, gastrointestinal, and cardiopulmonary involvements are rare. ${ }^{9}$

According to a cohort study, $13.3 \%$ of patients with digital ischaemia associated with cancer had cryoglobulinaemia. ${ }^{9}$ The largest series of MM that presented as cryoglobulin-related symptoms was reported by Payet et al. ${ }^{10}$ Most of the patients had skin lesions (71 [4\%]) among which only one patient presented with digital necrosis and gangrene. Treatment strategies for Type I cryoglobulinaemia with extensive necrosis involve plasmapheresis to quickly manage necrotising lesions and help their resolution. Specific chemotherapy prevents cryoglobulinaemia relapse and targets the underlying malignancy. In $\mathrm{MM}$, bortezomib and lenalidomide are one of the most effective first line therapeutic agents. $2,8,10$

Unfortunately, despite an adequate initial management, MM associated with Type I cryoglobulinaemia has a poor prognosis. Most of the cases reported in the literature had fatal evolution (Table 1). In a retrospective study of 1,228 patients with MM, patients with skin involvement had significantly decreased overall survival compared to those without skin involvement (median: 28 versus 57 months). ${ }^{16}$

Table 1: Characteristics of patients presented with multiple myeloma presented as cryoglobulin Type I-related digital necrosis.

\begin{tabular}{|c|c|c|c|c|c|c|}
\hline Case report & Age (years); sex & Bone marrow & MM type & ISS & Chemotherapy & Outcome \\
\hline $\begin{array}{l}\text { Narayanan } \\
\text { et al.,"11 } 2016\end{array}$ & 45; female & $\begin{array}{l}\text { Increase in } \\
\text { plasma cells }\end{array}$ & $\lg G-K$ & III & $\begin{array}{l}\text { Bortezomib, lenalidomide, } \\
\text { and dexamethasone }\end{array}$ & $\begin{array}{l}\text { Complete } \\
\text { remission }\end{array}$ \\
\hline $\begin{array}{l}\text { Ninomiya et } \\
\text { al.,12 } 2010\end{array}$ & 61; male & $\begin{array}{l}31 \% \text { plasma } \\
\text { cells }\end{array}$ & $\lg G-\lambda$ & II & $\begin{array}{l}\text { Vincristine, adriamycin, and } \\
\text { dexamethasone }\end{array}$ & Died \\
\hline $\begin{array}{l}\text { Solimando } \\
\text { et al.,13 } 2018\end{array}$ & 71; male & $\begin{array}{l}>90 \% \text { plasma } \\
\text { cells }\end{array}$ & IgG-K & 1 & $\begin{array}{l}\text { Bortezomib, melphalan, and } \\
\text { prednisone }\end{array}$ & $\begin{array}{l}\text { Partial } \\
\text { remission }\end{array}$ \\
\hline $\begin{array}{l}\text { Abdulla et } \\
\text { al., }{ }^{14} 2014\end{array}$ & 54; female & $\begin{array}{l}63 \% \text { plasma } \\
\text { cells }\end{array}$ & $\lg G-\lambda$ & - & $\begin{array}{l}\text { Dexamethasone, } \\
\text { cyclophosphamide, and } \\
\text { bortezomib }\end{array}$ & Died \\
\hline $\begin{array}{l}\text { Vacula et } \\
\text { al.,15 } 2010\end{array}$ & 68; male & $\begin{array}{l}\text { Diffuse } \\
\text { infiltration } \\
\text { by matured } \\
\text { plasma cells }\end{array}$ & $\lg G-\lambda$ & - & $\begin{array}{l}\text { Vincristine, idarubicin, and } \\
\text { dexamethasone }\end{array}$ & Died \\
\hline $\begin{array}{l}\text { The authors' } \\
\text { case }\end{array}$ & 68; female & $\begin{array}{l}30 \% \text { plasma } \\
\text { cells }\end{array}$ & $\lg A-\lambda$ & III & $\begin{array}{l}\text { Bortezomib, lenalidomide, } \\
\text { and dexamethasone }\end{array}$ & Died \\
\hline
\end{tabular}

ISS: Injury Severity Score; MM: multiple myeloma.

\section{CONCLUSION}

that requires specific management. It may lead to misdiagnosis and delayed treatment.

Digital necrosis is a rare and atypical Clinicians should be aware of this rare presentation of MM. Most often, it is related to Type I cryoglobulinaemia, a condition manifestation and consider MM diagnosis even in the absence of classical CRAB criteria. 


\section{References}

1. Kumar SK et al. Multiple myeloma. Nat Rev Dis Primers. 2017;3:17046.

2. Harel $\mathrm{S}$ et al. Clinico-biological characteristics and treatment of Type I monoclonal cryoglobulinaemia: a study of 64 cases. Br J Haematol. 2015;168(5):671-8.

3. Reisenbuckler C. Multiple myeloma and diagnostic imaging. Radiol Technol. 2014;85(4):391-410.

4. Rajkumar SV et al. International Myeloma Working Group updated criteria for the diagnosis of multiple myeloma. Lancet Oncol. 2014;15(12):e538-e48.

5. Tathineni P et al. Uncommon presentations of multiple myeloma. Cureus. 2020;12(6):1-7.

6. Brouet JC et al. Biologic and clinica significance of cryoglobulins: A report of 86 cases. Am J Med. 1974;57(5):775-88.

7. Kolopp-Sarda MN, Miossec P. Cryoglobulins: an update on detection, mechanisms and clinical contribution. Autoimmun Rev. 2018;17(5):457-64

8. Desbois $A C$ et al. Cryoglobulinemia: an update in 2019. Joint Bone Spine. 2019;86(6):707-13

9. Le Besnerais $M$ et al. Digital ischemia associated with cancer: results from a cohort study. Med (Balt). 2014;93(10):e47.

10. Payet $\mathbf{J}$ et al. Type I cryoglobulinemia in multiple myeloma, a rare entity: analysis of clinical and biological characteristics of seven cases and review of the literature. Leuk Lymphoma. 2013;54(4):767-77.

11. Narayanan $\mathrm{G}$ et al. Multiple myeloma presenting as cryoglobulinemia - a case report. Austin J Clin Case Rep. 2016:3(3):1096.

12. Ninomiya $\mathrm{S}$ et al. IgG type multiple myeloma and concurrent IgA type monoclonal gammopathy of undetermined significance complicated by necrotizing skin ulcers due to type I cryoglobulinemia. J Clin Exp Hematop. 2010;50(1):71-4

13. Solimando AG et al. Multiple myeloma that progressed as type I cryoglobulinemia with skin ulcers and foot necrosis: a case report. Med (Balt). 2018:97(39):e12355.

14. Abdulla $M$ et al. Multiple myeloma presenting as extensive limb gangrene. J Appl Hematol. 2014;5(3):107-10.

15. Vacula I et al. Cryoglobulinemia manifested by gangraene of almost all fingers and toes. Int Angiol. 2010;29(6):560-4.

16. Woo YR et al. Prevalence and clinicopathologic characteristics of multiple myeloma with cutaneous involvement: a case series from Korea. J Am Acad Dermatol. 2018;78(3):471-8.e4 